Cytogenet Genome Res 1967;6:305

\title{
The Chicago Conference, 1966
}

\section{An Editorial Note}

The system of human cytogenetic nomenclature proposed by the members of the Chicago Conference (1966) should permit greater ease and precision in communicating human karyotypic data. Moreover, this shorthand nomenclature should be adaptable to automated data processing and information retrieval systems. Researchers in non-human cytogenetics will also find that the general principles set forth and many of the symbols in the Chicago proposal are applicable to their work.

Prospective contributors to this journal are strongly urged to use the proposed system; however, its use will not be a prerequisite for publication in Cytogenet Genome Res. The Editorial Office will greatly welcome any comments readers may have regarding the Report of the Chicago Conference.

Reprints of the Chicago Conference : Standardisation in Human Cytogenet Genome Res. Birth Defects: Original Article Series, Vol. 2, No. 2 (1966) can be obtained at no cost by writing to the:

Medical Department

The National Foundation - March of Dimes

800 Second Avenue

New York, N.Y. 10017

21 Cytogenet Genome Res 61·), 1967 